\title{
Gestando a vida: esperança Severina
}

\section{Generating the life: Severina hope}

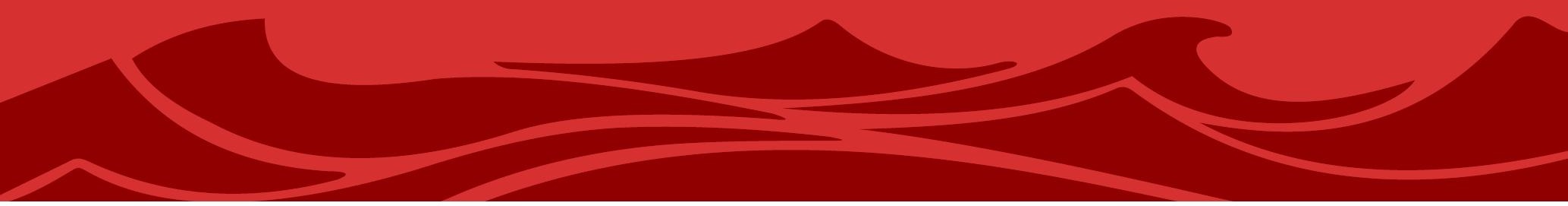

\section{Maria da Ajuda Luiz dos Santos}

Assistente Social; Mestrado em Ciências pela Pós-Graduação em Clínica Médica - UFRJ; Diretoria do CRESS/MG; Superintendente Regional de Saúde de Belo Horizonte.

E-mail:mariadajudal@gmail.com

\section{Daniel Emílio da Silva Almeida}

Farmacêutico; Mestre em Saúde Pública pela Faculdade de Medicina UFMG; Trabalhador da Prefeitura de Belo Horizonte.

E-mail: daniel.almeidamg@gmail.com

\section{Andreza Almeida Fernandes Alves}

Especialista em Gestão de Políticas de Saúde Informadas por Evidências; Especialista em Intervenção Psicossocial no Contexto de Políticas Públicas; Componente da Comissão de Reforma Psiquiátrica do Conselho Estadual de Saúde-CESMG.

E-mail: andrezaalmeidaf@gmail.com

\section{Natália Darck Silva de Freitas}

Assistente Social e especializando em Saúde Mental e Dependência Química.

E-mail:natalia.darcksilva@yahoo.com.br

\section{Resumo}

INTRODUÇÃO: Neste artigo buscamos realizar uma reflexão sobre o fenômeno das mães órfãs, considerando que a interrupção da maternagem de grupos socialmente desfavorecidos tem grandes semelhanças com as interrompidas durante a escravidão. ESTRATÉGIA DE ANÁLISE: Foram consideradas as recomendações no 05 e no 06/2014 do Ministério Público (MP) e Portaria no 03/2016 da Vara Cível da Infância e Juventude de Belo Horizonte (VCIJBH), assim como a análise crítica de narrativas e das próprias experiências dos autores, implicados com o fenômeno em questão. ANÁLISE: São colocadas em evidência no texto as ações fomentadas por parte de segmentos do judiciário, assim como a tensão gerada por dentro dos serviços de saúde, onde diversos projetos de cuidado estão em disputa. CONSIDERAÇÕES FINAIS: O texto discorre sobre como determinados grupos que se mostram "desviantes" são considerados como "anormais", sendo submetidos a lógicas de disciplinarização e controle, à mercê da justiça, do direito ao cuidado em saúde e à dignidade.

Palavras-chave: Violência contra a mulher; Escravidão; Poder familiar.

\footnotetext{
Abstract

INTRODUCTION: In this article we study the phenomenon of the compulsory separation of mothers and their children, considering that the interruption of the motherhood of socially disadvantaged groups have great similarities to the interrupted motherhood during slavery. STRATEGY
} 
ANALYSIS: Recommendations 05 and 06/2014 of the Public Prosecutor's Office and Ordinance No. 03/2016 of the Civil and Probate Court of Belo Horizonte were considered, as well as the critical analysis of narratives and the authors' own experiences, implicated in this situation. ANALYSIS: The actions promoted by judiciary segments are highlighted in the text, as well as the tension generated inside the health services, where several care projects are in dispute. FINAL CONSIDERATIONS: Finally, the text discusses how certain groups shown as "deviants" are considered "abnormal", being submitted to the logic of discipline and control, without justice, right to a better health care and to dignity.

Keywords: Violence against women; Slavery, Parenting

Introdução: um breve histórico das maternidades interrompidas

Este artigo busca trazer para a cena uma mulher, uma gestação, uma mistura de vidas nesse binômio inseparável: mulher, gravidez, gestação, parto, maternidade e maternagem. Uma elaboração da natureza alinhavada a uma construção cultural e social.

De olho na linha do tempo, na nossa história, essa construção não se traduz para todas as mulheres de forma horizontal. Vamos encontrar diferentes contextos produzidos e acatados em diferentes épocas por um conjunto de atores. Neste texto, pretendemos trabalhar essa construção genealógica sobre o olhar da lei e do cuidado em saúde, e como essas instituições vão se alinhando para produção de um conjunto de verdades, ${ }^{1,2}$ fortemente aparelhadas no viés técnico e legal, de acordo com o tempo, regras e normas instituídas.

Há tempos, quando nem homens, nem mulheres detinham o saber sobre o processo de reprodução, muito menos o papel do homem na gestação, acreditava-se que as mulheres pariam deuses e por isso lhes era outorgado a autoridade de governar. Muraro considera que o mundo era governado por meio de um preceito feminino. ${ }^{3}$ Com inferior força física, as mulheres governavam com valores femininos de persuasão, sedução e com rodízio de lideranças em meio a uma espécie de Lei Básica dos grupos pré-históricos de proteção à vida, solidariedade e partilha.

Engels ${ }^{4}$ chegou a afirmar que o estudo da história da família começa em 1861, com o Direito Materno de Bachofen. Para aquele, este autor formulava algumas teses, dentre elas a de que a filiação apenas podia ser contada por linha feminina, segundo o direito materno, e isso pôde ser constatado em todos os povos antigos. As mulheres, como mães, como únicos progenitores conhecidos de uma nova geração, gozavam de grande apreço e respeito, atingindo, a partir da perspectiva de Bachofen, o domínio absoluto (ginecocracia).

Muraro, ${ }^{3}$ escritora feminista da década de 70, explica que, após muitos anos de existência de sociedades de coleta (que viviam de frutos e 
pequenas caças), a humanidade necessitou de forças físicas na luta por novos territórios. Assim, foi se instituindo a lei do mais forte, e o homem passou a impor dominação sobre a mulher. ${ }^{3}$ A lei da competição foi se instaurando a partir do descobrimento sobre as leis e ciclo reprodutivo, há mais de dez mil anos, dando início a um novo período histórico. A competição refletiu diretamente nas relações humanas através da violência. Clãs, aldeias, cidades, cidades-estados, até os grandes impérios da Antiguidade, se tornaram etapas de uma história marcada desde a disputa por terras, subalternidade da mulher e instituição desta como escrava sexual.

Esta mesma autora ${ }^{3}$ conta que os homens trancavam as mulheres em casa para que estas se ativessem ao universo e afazeres domésticos como cozinhar, lavar, passar e, é claro, ter o maior número de filhos possível - uma mão-deobra barata voltada usualmente para trabalhos na terra ou mesmo atividades de guerra dispostos a dar a própria vida na conquista de terras e poder. Assim começou a hegemonia do patriarcado, a dominação do homem sobre a mulher e sobre todas as instituições: políticas, culturais e econômicas. ${ }^{3}$ Essas instituições, legitimadas por valores masculinos, idealizam na esfera pública a mulher reclusa no domínio privado, entregue à reprodução da vida imediata (fonte de satisfação) e à reprodução do próprio homem.

Para Engels, ${ }^{4}$ o desmoronamento do direito materno foi a grande derrota histórica do sexo feminino em todo o mundo. O homem apoderou-se da direção da casa e a mulher foi convertida em servidora, em escrava da luxúria do homem, em simples instrumento de reprodução da espécie. A diminuição da condição da mulher, verificada desde o período de glória dos gregos até os tempos clássicos, foi sendo, historicamente, ora reinventada, ora disfarçada, ora revestida por sentidos outros - menos perversos, mas de nenhuma maneira eliminada.

Num breve retorno no tempo vamos encontrar no Brasil, há pouco mais de um século, uma sociedade totalmente dependente da escravidão, advinda de escravos trazidos da Região Africana e vendida no mercado brasileiro. Nesta época, todo ser nascido nessa condição era patrimônio do senhor, ou seja, tratado como mera mercadoria com valor de troca. Nesta condição era bastante diferenciada a percepção da gestação, maternagem e cuidado de mãe com filhos. A maternagem de uma mulher negra significava uma "mãe de leite" para um filho de uma mulher branca, senhora dona da escrava. Esse leite que seria importante para alimentação do próprio filho, era prioridade para alimentar o filho da dona e, em geral, seu filho ficava em segundo plano. Somente na década de trinta do século dezenove, essa situação sofre uma mudança legal, com a aprovação da Lei do Ventre Livre, sancionada pela Princesa Regente, que vem tentar apaziguar os abolicionistas e as revoltas dos escravos e suas lideranças, espalhadas por todas as capitanias em prol da liberdade de todos. 
Esta Lei do Ventre Livre ${ }^{5}$ se caracteriza como um marco importante na correlação de forças no âmbito da escravatura e seus instrumentos legais. Entretanto, do ponto de vista da liberdade dessa criança que, pela lei, nasceria "livre", existiam condicionalidades impostas. A lei foi muito questionada à época e podemos verificar os motivos: o filho de escravo seria livre aos oito anos, após isso, trabalharia na infância para o seu senhor, e logo após esse período esse senhor teria a prerrogativa de ofertar trabalho ao menor até os vinte anos, desde que não lhe expusesse a maus tratos - o que seria verificado pelo juiz de menor. Além disso, a entrega desse menor para os órgãos de governo rendia títulos aos seus donos, e isso não significava liberdade, mas trabalho onde o menor fosse acolhido. A liberdade desse negro poderia ser comprada pelos seus parentes ou outros, desde que o dono fosse ressarcido no valor cotado no mercado, pela condição aferida de saúde do menor. Portanto, por essa lei, podemos afirmar que muito pouco do binômio mãe e filho ou da maternagem, no tangente a mulheres negras nessa época, foi alterado.

Não é possível atuar em favor da igualdade, do respeito aos demais, do direito à voz, à participação, à reinvenção do mundo, num regime que negue a liberdade de trabalhar, de comer, de falar, de criticar, de ler, de discordar, de ir e vir, a liberdade de ser. ${ }^{6: 193 .}$

Mesmo com o final da escravidão não há alterações significativas no país para essas mulheres e seus filhos por um longo período do ponto de vista legal, institucional ou cultural. Há um processo lento, constituído na luta cotidiana e no emaranhado dos procedimentos instituídos/instituintes ${ }^{7}$ e vice-versa na construção societária brasileira.

Podemos destacar como um ato importante nesse cenário as leis trabalhistas que vieram estipular para todos os trabalhadores uma carga horária máxima de trabalho semanal, descanso remunerado e férias anuais e, no caso específico da mulher gestante, uma garantia de licença maternidade para todas as trabalhadoras com carteira assinada ou com emprego em regime próprio de previdência durante dois meses a contar do início de seu afastamento para o parto. Do ponto de vista legal, podemos caracterizar a licença maternidade como arcabouço jurídico de garantia da maternagem no Brasil. ${ }^{8}$

Nosso esforço em trazer parte desse processo de conformação das leis, luta das mulheres, composições e instrumentos jurídicos e normativas que vão conformar o direito de ser mulher e mãe vem no sentido de trazer para a cena o lugar que essa sociedade desenha para a mulher, análise que carece de muito delicadeza, pois não podemos nos distanciar dos sujeitos que se implicam, são implicados, ou que por concepção e/ou escolha já se encontram nesse lugar por ser mulher e viver nessa sociedade. ${ }^{9}$

Os entraves à maternagem nos dias atuais e as estratégias e ferramentas de análise

Trazendo para uma temporalidade mais atual, pretendemos visitar legislações de abrangência 
definida. Sendo assim, vamos trazer para a cena as Recomendações da 23a Promotoria de Justiça da Infância e Juventude Cível de Belo Horizonte de $2014^{10,11}$ que dispõem sobre a necessidade dos serviços de saúde públicos informarem a Vara da Infância e Juventude sobre o nascimento de filhas e filhos nascidos de mães vulneráveis, bem como a Portaria no 03 da Vara Cível da Infância e da Juventude de Belo Horizonte de 2016, ${ }^{12}$ que obriga as equipes das maternidades públicas a comunicarem em 48 horas à Vara o nascimento de filhos de mães consideradas em situação de vulnerabilidade, como as que usam de Crack e outras drogas, para tomada de decisão por parte do judiciário sobre a guarda do filho.

Esta produção é mais um dos esforços que dispensamos para, aqui nesse contexto, desnudarmos o nascedouro dessas normativas jurídicas, seus postulados e regramentos, e para que possamos mapear seus atores, suas narrativas e como essa construção se dá no terreno do cotidiano dos serviços de saúde ao longo do tempo. Propomos um esforço de análise que nos ajude a compreender e fazer apostas no espaço do cuidado em saúde.

Como estratégias de análise e construção do conhecimento, seguimos neste texto com o intuito de confeccioná-lo da maneira mais horizontal, simétrica e coletiva possível. Não buscamos nos colocar como sujeitos do conhecimento, submetendo o cenário a estruturas teóricas prévias e determinadas. Julgamos que ganhamos em riqueza ao nos envolvermos com os sujeitos e coletivos das situações problematizadas, e não só nos colocando como meros informantes, mas como sujeitos ativos no processo de produção do conhecimento. ${ }^{13}$

Portanto, nesta produção, apresentaremos diversas perspectivas de análises, sem o objetivo que estas coadunem entre si em uma extensa estrutura teórica enrijecida e interpretativa da situação. Buscamos aqui apresentar várias ferramentas, provenientes até de perspectivas de mundos diferenciadas, $\mathrm{e}$ com seus respectivos esforços problematizadores, num esforço crítico e múltiplo dos cenários analisados.

Os pesquisadores do Observatório de Políticas e Cuidado em Saúde da UFMG, autores desse artigo, foram respaldados pelos pareceres dos Comitês de Ética em Pesquisa (no 1.847 .486 CEP/SMSA-BH; $n$ 요 2.264.660 CEP/UFMG e n으 1.756.736 CEP/Nacional).

A reedição atual de arranjos passados: paralelos entre a escravidão e a maternagem interrompida

As recomendações e portaria provenientes, respectivamente, do Ministério Público e Judiciário, encerram um enunciado que clama pelo cuidado com o mais frágil, aquele que ainda não tem voz e que, portanto, diante da ausência de "capacidade" de sua genitora em Ihe ofertar cuidados básicos e segurança perante a vida, deveria ser entregue ao Estado 
para que este proporcione a esse indivíduo outras possibilidades de vida, antecipando pelo viés jurídico o fracasso dessa maternagem ou mesmo a convivência desse na família extensa. Isso nos remete ao passado, onde a Lei do Ventre Livre, de certa forma, vem garantir de forma legal que essa mulher negra e despossuída de bens econômicos, diante de algumas condicionalidades, pudesse exercer sua maternagem, podendo dizer que esse filho Ihe pertencia. $\mathrm{Na}$ atual conjuntura, o Estado aparece como o Senhor da Escrava, pois toma para si, como o governo de todos, o lugar da mãe e da família, impondo em quais condições essa criança deve viver e como.

Importante neste contexto desnudar algumas narrativas de sujeitos implicados nesse processo, que mesmo quando são de esferas institucionais distintas, em determinado momento se coadunam, aparecendo claramente um certo ponto de vista, em detrimento do ponto de vista do sujeito a quem a ação será aplicada. Como numa carta lacrada, onde o selo seria o carimbo, contendo as palavras cuidado da criança, o contexto da carta é bastante pretensioso e significativo, sendo que nele está contido todo um jogo de poder, onde poderíamos ler o que dizem nas entrelinhas os vários atores, do jogo de palavras à constituição de verdades: "Como pode uma moradora de rua cuidar de uma criança?", "A família extensa já é tão desestruturada, como acatar mais um membro?", "A criança é prioridade absoluta frente a lei, portanto temos que agir, a fim de zelar pelo seu bem estar.",
"Mulheres em uso de álcool ou outras drogas não podem amamentar uma criança.", "A quantidade de álcool ou outras drogas torna essa mulher incapaz para o mundo trabalho, logo o sustento dessa criança está comprometido", "Em uma casa sem quartos para a criança, onde fica o bom alojamento para este bebê?". Estes e muitos outros ditos são expressos de forma natural por alguns técnicos da rede de saúde que trabalham nessas maternidades e igualmente por agentes do poder judiciário; coadunam com o arcabouço jurídico definidor do destino de mães consideradas em situação de "vulnerabilidade" e de seus filhos que, de acordo com essa visão de mundo, deixam de ser seus.

Contudo, a carta tem várias palavras e muitos outros enunciados e, na busca de compreensões acerca de seus dizeres e do não dito sobre ao assunto, é preciso adentrar no universo das relações de poder, em como é visto o papel do Estado por esses sujeitos dessa ação e de que lugar fala cada um. Neste cenário, temos um ponto chave escamoteado, mas necessário para compreender até onde pode chegar o sujeito da verdade: as mulheres cujos filhos são retirados são pobres, pardas ou negras, alguém a quem o Estado vem negando vários direitos ao longo da história. Ele reedita um retorno presente na nossa formação social: que lugar essa mulher ocupa nesses cenários e o quanto valem essas vidas nessa conformação? $\mathrm{E}$ ainda encontramos outra verdade velada: a da presunção de culpa dos sujeitos fora das regras sociais, talvez aqui o ponto mais perverso da 
falácia protetora. Neste sentido, retirar esse filho significaria a garantia de que ele não será mais um delinquente. Eis o xeque mate dos que querem assegurar tal medida.

Essa mulher já é uma condenada pela lei, portanto aplica-se ao filho presumidamente o código penal ao nascer, pois presumidamente será um fora da lei. Trata-se de um importante ponto de retorno. As Recomendações n응 05 e no 06 e Portaria no 03 aproximam-se de uma revogação da Lei do Ventre Livre. Tal ação nos remete ao que Foucault nomeou de poder disciplinar:

O poder disciplinar é com efeito um poder que, em vez de se apropriar e de retirar, tem como função maior 'adestrar'; ou sem dúvida adestrar para retirar e se apropriar ainda mais e melhor. A disciplina 'fabrica' indivíduos; ela é a técnica específica de um poder que toma os indivíduos ao mesmo tempo como objetos e como instrumentos de seu exercício. 14:143

Foucault diz em seu livro Vigiar e punir ${ }^{14}$ sobre os corpos dóceis, trazendo para a realidade atual, dentro do contexto de instituições totais, que as semelhanças "foucaultianas" começam desde os serviços de saúde que aquela mãe teria que acessar para parir seu filho, até os abrigos que institucionalizam essas crianças. Estes corpos de mães e filhos são corpos uniformizados, domesticados, adestrados para atender a um sistema punitivo. No caso da mãe, se ela é uma usuária de droga e pobre, é punida com a ausência do filho, sem ser questionada sobre o desejo de permanecer ou não do filho. Ser mãe para essas mulheres é descumprir uma norma moral, hipócrita e moralista que a sociedade prega como correta.

A imagem da criança institucionalizada pelo Estado, assim como nas prisões e demais instituições totais, ${ }^{15}$ correspondem à tentativa de adestramento de indivíduos e expropriação de direitos já descritos no Estatuto da Criança e do Adolescente (ECA). ${ }^{16}$ Mães e filhos já marginalizados são punidos. A retirada dessas crianças do seio de suas mães tem cor, raça e classe social, como podemos observar pelo perfil dos casos ocorridos e pela não aplicação destas normativas em hospitais com perfil de atendimento de planos de saúde ou particulares. O uso de álcool e drogas e as diversas faces da vulnerabilidade social que algumas mães se encontram são uma das principais justificativas para a institucionalização, considerando-se estas mulheres como incapazes de responsabilizar-se por seus filhos. Essa verdade produzida adquire um valor moral pelas autoridades que apoiam e efetivam a portaria, justificando o “abrigamento compulsório". Nada mais cruel.

Não se deve condenar ou punir esta mãe. Quando a justiça toma a decisão por si, sem o respaldo das informações necessárias sobre a família extensa e rede social, ou informações sobre todo o investimento, muitas vezes dispendido pelas redes de saúde, assistência social e outros apoiadores, a retirada dos bebês só gera uma violência entre as partes.

Podemos reconhecer outras construções críticas ofertadas coletivamente a partir de 
diversos pensadores. Além das constituições das sociedades disciplinares, podemos observar estratégias que atravessam o governo das populações, de forma biopolítica. É o que Deleuze veio nos oferecer como ferramenta de análise, que seriam as sociedades de controle. ${ }^{17}$ Desta perspectiva, as estratégias de controle se multiplicam, intensificam, e atingem planos subjetivos. 0 judiciário, mas também outros planos societários, como trabalhadores de saúde e a própria população, se vê repetindo certas palavras de ordem, onde a população que não trabalha, consome ou não investe seus desejos, como o indicado capitalisticamente, se torna empecilho societário, anormais, não-humanos ${ }^{17}$ e, portanto, passíveis de qualquer intervenção.

Os posicionamentos ético-políticos dos serviços de saúde: entre a moralização, o esgotamento e a resistência

Nas equipes de cuidado e atenção à mulher nas maternidades vamos encontrar posicionamentos diferenciados e que precisamos escutar muito cuidadosamente. Temos, por exemplo, um conjunto de atores nessa esfera que veio e vem fazendo questionamentos às normativas legais e ações no sentido de garantir a maternagem dessa mulher e de buscar meios técnicos e operacionais para que essa mãe retorne ao seu território, ou que tenha um abrigamento conjunto, numa tentativa de construção de laços afetivos, vínculo com a equipe do território onde a mesma reside e possibilidades de autonomia, para assim construir sua própria trajetória de vida.

No entanto, como lidamos com sujeitos que portam valores, visões de mundo, também vamos encontrar nesse universo do "cuidado" atores que se dizem mais seguros com as normativas legais, uma vez que a prática de acionar o judiciário nesses chamados casos complexos sempre fez parte do seu fazer profissional. Aqui precisamos destacar que, em situações de esgotamento de todas as outras possibilidades, também entenderíamos essa necessidade, mas no cotidiano da ação, corremos o risco de entrar no campo do descuidado e repasse de responsabilidade desses para um ator externo ao campo da saúde, ou seja, o campo da lei.

Além disso, tivemos acesso a diversos relatos apontando que alguns agentes de saúde foram importantes apoiadores da formulação destas normativas, constituindo visões de mundo a partir das quais as mães eram destituídas de seus papéis de sujeitos, tornadas incapazes e destituídas de seu direito de maternagem por apresentarem comportamentos "desviantes" ou "anormais". Tais posturas tensionam com aquelas que vêm denunciando essa coerção praticada por diversos atores, dentre os quais profissionais da própria equipe de saúde para que as normativas sejam seguidas.

A dimensão que esse cuidado vem tomando, muitas vezes perdendo sua potência cuidadora, o ascende a uma dimensão punitiva "inserida 
num processo de domínio e controle das forças corporais para a produção de docilidade, isto é, de submissão e de utilidade". ${ }^{18: 20}$ A mulher, nesse contexto, é invisibilizada enquanto sujeito de direitos, percebida como sem capacidade e autonomia para garantir sua reprodução. A energia produtiva dessas mulheres não está à mercê do mercado e, neste sentido, ela é vista como incapaz de produzir mais-valia. Portanto, talvez ela não mereça ser protegida nem enquanto objeto.

Considerando essas reflexões, aqui propomos uma breve apresentação de questões problematizadoras sobre a intervenção sobre esse ser/objeto institucionalizado: onde fica a autonomia do trabalho vivo em ato ${ }^{19}$ Estaríamos perdendo essa autonomia? Até que ponto esta autonomia dos trabalhadores de saúde está voltada para o processo de cuidar ou, em um caminho contrário, busca uma normalização dos sujeitos que não seguem estritamente o que valoram moralmente?

Ou como os profissionais de saúde, com um determinado jeito de ver o mundo, repassam o ato de cuidar para um agente externo? Que valoração de mundo esse ator de fora defende ao dizer que o sujeito sem voz é a criança e que esta precisa ser "salva" desse contexto familiar adverso ou inexistente? Não estariam as instituições jurídicas e políticas do Estado e a estrutura econômica da sociedade civil alienando essas mulheres delas mesmas ao mostrarem um formato de proteção que alimenta um sistema de punição, o qual serve apenas para proteger as condições fundamentais da sociedade de produtores de mercadoria e não mais de vida? Foucault já dizia que todo sistema punitivo como disciplinador é uma faceta da microfísica do poder, inserido num processo de domínio que escancara uma guerra civil contra segmentos da população "que são excluídos do mercado de trabalho e que não têm como sobreviver" ${ }^{\text {18:22 }}$, portanto, têm suas condutas criminalizadas.

Neste sentido, em nome de uma maternagem idealizada, consumidora incessante dos devidos bens de consumo e devidamente encaixada na produção capitalista, essas mulheres e seus bebês estão sendo intensamente submetidas a estratégias patologizantes e segregatórias, a partir das quais os desviantes se tornam riscos iminentes a serem controlados. ${ }^{17}$

\section{Considerações finais}

Temos a oportunidade de visualizar a reedição de fenômenos antigos no cenário analisado não só em Belo Horizonte, mas em todo o país, algo observado pelo aumento da publicização dos meios de comunicação e produções acadêmicas. A escravidão e determinação dos não-humanos apresentam novas roupagens, justificativas, normativas e construções simbólicas.

Tais ações disciplinares se redobram e ganham fôlego em meio a estratégias biopolíticas e de controle que se forjam societariamente nos 
campos normativos e simbólicos dos novos não-humanos. ${ }^{17}$ Neste cenário, observamos não só o conflito entre as práticas de saúde, justiça e democracia, mas dos limites da ética societária atual. É uma tensão que se reatualiza entre práticas que defendem não só o direito social a redes de proteção social, mas arranjos societários mais solidários que resguardem a defesa da diferença, dignidade e liberdade ${ }^{17}$ frente a estratégias de disciplinarização, normalização e exclusão. Em suma, reinseremse questões relativas a própria escravidão.

\section{Referências}

${ }^{1}$ Foucault M. Microfísica do poder. Rio de Janeiro: Edições Graal; 2001.

'Land MGP. Genealogia: uma investigação criminal aparentemente equivocada: uma conversa com o texto "Nietzsche, a genealogia e a história" de Michel Foucault. In: Merhy EE et al. (orgs). Avaliação compartilhada do cuidado em saúde: surpreendendo o instituído nas redes. 1. ed. Rio de Janeiro: Hexis; 2016. p.423-427. (Políticas e cuidados em saúde; 1)

${ }^{3}$ Muraro RM. Mais Lucro: valores humanos na construção da empresa. Rio de Janeiro: Editora José Olympio; 2006.

${ }^{4}$ Engels FE. A origem da família, da propriedade privada e do Estado - (1884). 3.ed. São Paulo: Editora Escala; 2009. Coleção Grandes Obras do Pensador Universal, 02.

${ }^{5}$ Lei de 7 de Novembro de 1831; publicação original - Lei do Ventre Livre. Portal Câmara dos Deputados. www2.camara.leg.br. 1831 [citado 29 nov 2017]. Disponível em: http://www2.camara.leg.br/legin/fed/lei_sn/18241899/lei-37659-7-novembro-1831-564776-publicacaooriginal-88704-pl.html

${ }^{6}$ Freire P. Cartas a Cristina. 2. ed. São Paulo: Unesp; 2002.

${ }^{7}$ Baremblitt GF. Compêndio de análise institucional e outras correntes: teoria e prática. 5 ed. Belo Horizonte: Biblioteca Instituto Felix Guattari; 2002.

${ }^{8}$ Decreto-Lei N. 0 5.452, de 1 ㅇ de maio de 1943. Aprova a Consolidação das Leis do Trabalho. Diário Oficial da União. 9 de ago 1943.

${ }^{9}$ Merhy EE. O conhecer militante do sujeito implicado: o desafio em reconhecê-lo como saber válido. In: Franco TB, Peres MA de A, Foschiera MMP, Panizzi M (orgs). Acolher Chapecó: uma experiência de mudança do modelo assistencial, com base no processo de trabalho. São Paulo: HUCITEC; 2004.

${ }^{10}$ Recomendação no 5/PJIJCBH/MPMG, de 16 de junho de 2014. Recomendação aos médicos, profissionais de saúde, diretores, gerentes e responsáveis por maternidades e estabelecimentos de saúde. Belo Horizonte: Ministério Público do Estado de Minas Gerais; 2014.

${ }^{11}$ Recomendação no 6/ PJIJCBH/MPMG, de 06 de agosto de 2014. Recomendação aos médicos, profissionais de saúde, Agentes Comunitários de Saúde, gerentes e responsáveis por Unidades Básicas de Saúde. Belo Horizonte: Ministério Público do Estado de Minas Gerais; 2014.

${ }^{12}$ Portaria no 3/VCIJBH, de 22 de julho de 2016. Dispõe sobre o procedimento para encaminhamento de crianças recémnascidas e dos genitores ao Juízo da Infância e da Juventude, assim como, oitiva destes, nos casos de graves suspeitas de situação de risco, e sobre o procedimento para aplicação de medidas de proteção. Diário do Judiciário Eletrônico TJMG. [Internet] 201625 jul [citado 04 mai 2017]:29-33. Disponível e m: http:// ftp.tjmg.jus.br/juridico/diario/index.jsp?dia=2207\&completa=2inst\%7Cadm.

${ }^{13}$ Abrahão AL et al. O pesquisador IN-MUNDO e o processo de produção de outras formas de investigação em saúde. In: Gomes MPC, Merhy EE (Org.). Pesquisadores In-Mundo: um estudo da produção do acesso e barreira em Saúde Mental. Porto Alegre: Editora Rede Unida; 2014. p.155-170.

${ }^{14}$ Foucault M. Vigiar e punir: nascimento da prisão. Petrópolis: Vozes; 1999.

${ }^{15}$ Goffman E. Manicômios, prisões e conventos. 7. ed. São Paulo: Editora Perspectiva; 2001.

${ }^{16}$ Lei № 8.069, de 13 de julho de 1990. Estatuto da Criança e do Adolescente. Diário Oficial da República Federativa do Brasil, Brasília. [Internet] 1990 [citado 21 ago 2017]. Disponível em: http://www.planalto.gov.br/ccivil_03/ LEIS/L8069.htm. 
${ }^{17}$ Merhy EE. Anormais do desejo: os novos não humanos? Os sinais que vêm da vida cotidiana e da rua. In: Grupo de Trabalho de Álcool e Outras Drogas. Drogas e cidadania em debate. Brasília: Conselho Federal de Psicologia; 2012. p.9-18.

${ }^{18}$ Santos JC. O sistema penal como exploração do proletariado. In: Mattos V, Magalhães C, Magalhães JLQ (org). Desconstruindo práticas punitivas. Transcrição Ricardo Henrique de Carvalho Lara. Belo Horizonte: Grupo de Amigos e Familiares de Pessoas em Privação de Liberdade/CRESS 6ạ Região; 2012.

${ }^{19}$ Merhy EE, Feuerwerker LCM. Novo olhar sobre as tecnologias de saúde: uma necessidade contemporânea. In: Mandarino ACS, Gomberg E(org.). Leituras de novas tecnologias e saúde. São Cristóvão: Editora UFS; 2009.285 p. 